\title{
Impact of Severe Sarcopenia on Rehospitalization and Survival One Year After a TAVR Procedure in Patients Aged 75 and Older
}

\author{
Céline Brouessard' \\ Anne Sophie Bobet' \\ Marie Mathieu' \\ Thibaut Manigold ${ }^{2}$ \\ Pierre Paul Arrigoni ${ }^{3}$ \\ Thierry Le Tourneau ${ }^{4}$ \\ Laure De Decker' \\ Anne-Sophie Boureau ${ }^{1,4}$ \\ 'Department of Geriatrics, University \\ Hospital, Nantes, France; ${ }^{2}$ Department of \\ Cardiology, Institut du Thorax, University \\ Hospital, Nantes, France; ${ }^{3}$ Department of \\ Radiology, University Hospital, Nantes, \\ France; ${ }^{4}$ Université de Nantes, $\mathrm{CHU}$ \\ Nantes, CNRS, INSERM, Institut du \\ Thorax, Nantes, F-44000, France
}

Correspondence: Anne-Sophie Boureau Department of Geriatrics, University Hospital, Nantes, 44093, France Tel +33240165046

Email annesophie.boureau@chu-nantes.fr
Background: Transcatheter aortic-valve replacement (TAVR) reduces mortality and improves quality of life in patients with severe aortic valve stenosis. One third of patients have no benefit one year after TAVR. Sarcopenia, an age-related loss of skeletal muscle mass, is associated with increased physical disability and mortality. The main purpose was to evaluate the impact of severe sarcopenia on rehospitalization one year after TAVR in older patients.

Methods: All patients aged $\geq 75$ referred for a TAVR in 2018 were included. Severe sarcopenia was defined by a loss of skeletal muscle mass defined on CT-scan measurement associated with a gait speed $\leq 0.8 \mathrm{~m} / \mathrm{s}$. The main outcome was rehospitalization one year after TAVR.

Results: Median age of the 182 included patients was 84 , and $35 \%$ had an unplanned hospitalization at one year. Severe sarcopenia was diagnosed in 9 patients (4.9\%). Univariable analysis showed that gait speed was a factor associated with readmission $[\mathrm{HR}=0.32,95 \% \mathrm{CI}(0.10-0.97), \mathrm{p}=0.04]$ but not severe sarcopenia. In multivariable analysis, only diabetes was significantly associated with rehospitalization $[\mathrm{HR}=2.06,95 \% \mathrm{CI}(1.11-$ 3.84), $\mathrm{p}=0.02]$. Prevalence of severe sarcopenia varied according to different thresholds of skeletal muscle mass on CT-scan.

Conclusion: Even though severe sarcopenia was not correlated with rehospitalization and mortality at one year after TAVR, our results emphasize the changes in the prevalence according to cutoff used. It highlights the need to define standardized methods and international threshold for sarcopenia diagnosis by CT-scan measurements, in general population and for patients with valvular heart disease.

Keywords: sarcopenia, older, aortic stenosis, transcatheter aortic valve replacement, hospitalization

\section{Introduction}

Aortic stenosis is the most common valve disease in patients aged 75 years and older. ${ }^{1}$ Severity and prognosis depend on echocardiographic criteria and the symptomatology presented by the patient. For older patients, curative treatment indication is based on two criteria: aortic stenosis considered severe on echocardiographic assessment with symptoms (exertional dyspnea, exertional syncope and angina). ${ }^{2}$ The curative treatment is valve replacement, by conventional surgery or transcatheter aortic valve replacement (TAVR). This minimally invasive aortic valve replacement under angiographic control reduces mortality at 2 years and improves quality of life by reducing dyspnea., 
However, one year after TAVR, 15 to $30 \%$ of patients have no benefit of the intervention with no improvement in quality of life, severe complications or death. ${ }^{4,5}$ Geriatric syndromes are associated with the occurrence of these events. ${ }^{6,7}$ Sarcopenia is an interesting and understudied syndrome in this context. The term "sarcopenia" was proposed in 1989 by Rosenberg. ${ }^{8}$ Sarcopenia is defined as the loss of muscle strength secondary to a progressive and generalized loss of skeletal muscle mass with aging. ${ }^{9}$ The evaluation of sarcopenia is based on the measurements of muscle strength and muscle mass. Severe sarcopenia is defined by low muscle mass and loss of muscle strength with altered physical performances. ${ }^{9}$ The impact of sarcopenia on older people is significant in terms of morbidity, disability, quality of life, high costs of health care, and mortality. ${ }^{10-12}$ Thus, an increased risk of death, rehospitalization or complications can be expected after TAVR in sarcopenic patients. In the literature, some studies highlighted the impact of sarcopenia on the increase in mortality, rehospitalization or high resource utilization after TAVR, while others found diverging results. ${ }^{13-21}$ But none of these studies included a complete geriatric assessment with physical performance and complete nutritional assessment. The main purpose of our study was to evaluate the impact of severe sarcopenia on rehospitalization and survival one year after a TAVR procedure in patients aged 75 years and older.

\section{Methods}

\section{Study Population}

Between January 2018 and January 2019, all patients aged 75 and older hospitalized for TAVR procedure in the Cardiology Department of the Nantes University Hospital (France) were all screened for inclusion in our retrospective monocentric observational study. The decisions on aortic valve stenosis treatment (surgical procedure, TAVR or medical treatment) and the details of procedures (eg, valve type, valve size, access route, and type of anesthesia) were finalized through discussions by a multidisciplinary heart team after the same standardized preoperative general evaluation including a comprehensive geriatric assessment.

The inclusion criteria were 1) 75 years old and older, 2) severe symptomatic aortic valve stenosis or bioprosthesis aortic valve degeneration treated by TAVR, 3) comprehensive pre-operative geriatric assessment including physical performance and nutritional assessment, 4) with CT-scan of the chest, abdomen and pelvis. The following patients were excluded: patients under legal protection, patients for whom TAVR was done as an emergency procedure or salvage intervention. All patients received TAVR procedure, by transfemoral, carotid or apical approach, at the Nantes University Hospital Cardiology Centre.

The study was conducted in accordance with the ethical standards set forth in Declaration of Helsinki (1983). This study was approved by the local ethics committee, Groupe Nantais d'Ethique dans le domaine de la Santé (GNEDS), which waived the need for informed consent in keeping with legislation on retrospective analyses of anonymized data.

\section{Baseline Data}

As part of the TAVR preprocedural assessment done in the 2 months before intervention, a comprehensive geriatric assessment was performed by a geriatrician for all patients to assess comorbidities, physical performances, functional status, cognition, depression, and nutritional status. The complete definition of the comprehensive geriatric assessment (CGA) variables is detailed in supplementary data. In our study, physical performances were assessed by gait speed with the 4-meter gait speed test.

During the same time, all patients underwent a preprocedural CT evaluation which included chest, abdomen, and pelvis acquisition. The images were recorded on the Millennium PACS software. Skeletal muscle area was measured at the inferior margin of L3 vertebra on the abdominal scan of pre-TAVR CT (axial CT images at L3 level with both transverse processes fully visible). The level of the section was determined from the MPR application of the Millennium PACS software by adjusting the axial and sagittal sections centered on L3. A single crosssectional CT image of L3 was selected and used to measure skeletal muscle area which was performed in a semi-automated fashion with manual "polygone" tracing tool and setting the density threshold between -29 and 150 Hounsfield units (HU). The skeletal muscle area included abdominal skeletal muscles, para-vertebral muscles and psoas $\left(\mathrm{cm}^{2}\right)$. The L3 skeletal muscle mass index (SMI) was calculated as skeletal muscle area divided by height squared $(\mathrm{cm} 2 / \mathrm{m} 2)$. For psoas mass index $\left(\mathrm{cm}^{2} /\right.$ $\mathrm{m}^{2}$ ), measurements of the left and right psoas muscles were summed $\left(\mathrm{cm}^{2}\right)$, then indexed to the square of the patient's height $\left(\mathrm{m}^{2}\right)$. 
CT images of 50 randomly selected patients were independently analyzed by a second observer to obtain interobserver reproducibility.

Severe sarcopenia criteria were defined according to European Working Group on Sarcopenia in Older People including: ${ }^{9}$

- Loss of skeletal muscle mass index (SMI) measured on CT-scan

- Gait speed measurement $\leq 0.8 \mathrm{~m} / \mathrm{s}$

Because no international consensus exists on total SMI threshold, cut-off values for loss of skeletal muscle mass were defined according to previously published studies: total skeletal muscle index (total SMI) $<55.4 \mathrm{~cm}^{2} / \mathrm{m}^{2}$ in men and $<38.9 \mathrm{~cm}^{2} / \mathrm{m}^{2}$ in women. ${ }^{16,18-20}$

To discuss the results, prevalence of severe sarcopenia was assessed using the other previous total skeletal muscle index thresholds. ${ }^{13-21}$

\section{Study End Points}

The main outcome was rehospitalization one year after aortic valve replacement by the TAVR procedure. The secondary outcome was death at one year after aortic valve replacement by the TAVR procedure.

For all patients, the general practitioner (GP) was contacted by phone to collect data concerning rehospitalization (numbers, post-TAVR delay, reason) and/or the occurrence of a death (post-TAVR delay, reason). If either GP or cardiologist had not had contact with the patient at one year, the patient was considered alive and without readmission during the first year after TAVR.

\section{Statistical Analysis}

For the participants' baseline characteristics, quantitative variables were described as mean \pm SD if normally distributed and as median and Interquartile Range (IQR) otherwise and were compared using Student's $t$-test or Mann-Whitney $U$ test respectively. Qualitative variables were described as number $(\%)$ and were compared using Chi-squared test or Fisher's exact test depending on size $(>5)$. Univariable Cox regression was used to identify factors associated with rehospitalization or death. All baseline variables with a p-value < 0.20 in univariable analysis and all the variables already known to be confounding factors were included in multivariable Cox regression model. The hazard radio (HR) and the confidence intervals $(\mathrm{CI})$ were presented in the charts.
Reproducibility of the measurement methods was assessed by Spearman's correlation coefficients and Interclass correlation coefficient.

All p-values were two-sided and p-value less than 0.05 was considered statistically significant.

All statistics were performed using the $\mathrm{R}$ statistical package, version 3.6.2 ( $\mathrm{R}$ Foundation for Statistical Computing, Vienna, Austria).

\section{Results}

Between January 2018 and February 2019, 362 patients $\geq 75$ years had a pre-operative geriatric assessment in Nantes University Hospital for severe aortic stenosis and 215 were referred for a TAVR procedure. CT-scan could not be analyzed for five patients (performed in other hospital), geriatric assessment including gait speed was not evaluated for 28 patients. Finally, 182 patients were included in the study (Figure 1).

\section{Patients' Characteristics}

The median age of the study population was 84 years $(\mathrm{IQR}=81-86)$, and $50 \%$ were men. Table 1 shows the detailed baseline characteristics of the whole population and of rehospitalized patients. The mean of total SMI was $52.5 \mathrm{~cm}^{2} / \mathrm{m}^{2}$. The mean gait speed was $0.90 \mathrm{~m} / \mathrm{s}( \pm 0.23)$. Severe sarcopenia (loss of skeletal muscle mass and gait speed $<0.8 \mathrm{~m} / \mathrm{sec}$ ) was present in 9 patients $(4.9 \%)$.

\section{Reproducibility}

For total SMI, Spearman's correlation coefficient was 0.91 ( $p$-value $<0.001)$ and the ICC was at $0.93(p<0.001)$.

\section{Primary Outcome}

Five general practitioners could not be join to collect information concerning post-TAVR condition, these patients were considered alive and without rehospitalization at one year. During 12-month follow-up, 64 patients underwent unplanned hospitalization (35\%) of whom $54.7 \%$ were men. Most of the rehospitalizations were related to a cardiological complication such as heart failure, heart attack, atrial fibrillation or third-degree atrioventricular block (21 patients). The other reasons for rehospitalization were geriatric complication (16 patients for falls, delirium, malnutrition ...) or other reasons such as infections (4 patients) or gastro-intestinal bleeding ( 8 patients) ....

Univariable statistical analysis showed that gait speed was a factor associated with readmission $[\mathrm{HR}=0.32,95 \%$ 


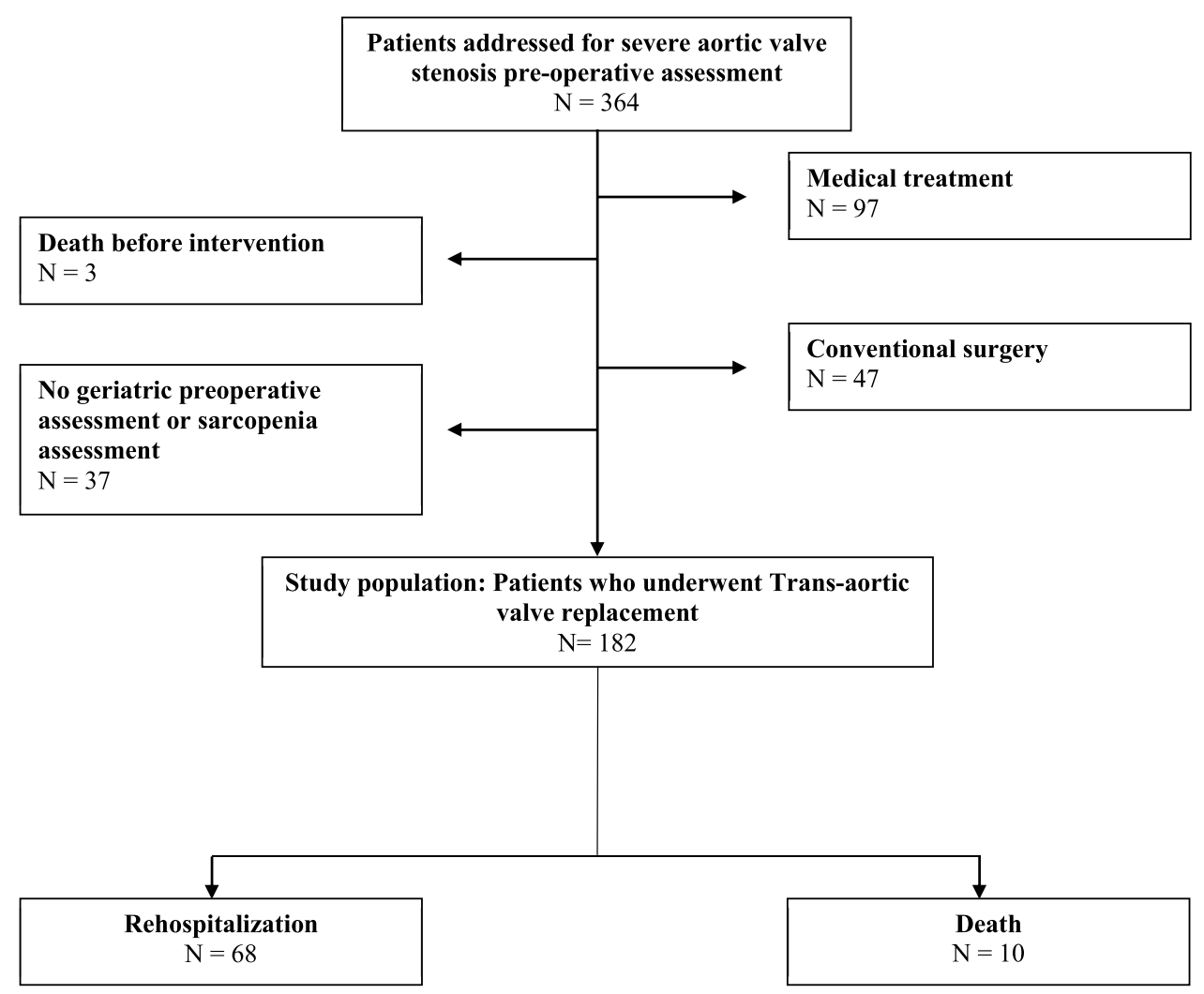

Figure I Patients flow diagram.

Abbreviations: TAVR, transcatheter aortic valve replacement; GP, general practitioner.

CI $(0.10-0.97), \mathrm{p}=0.04]$ in contrast to severe sarcopenia [HR $=0.98,95 \%$ CI $(0.14-2.38), \mathrm{p}=0.45]$ or total SMI [HR $=1.00,95 \%$ CI $(0.97-1.03), p=0.78]$ (Table 1S in supplementary data). Other peroperative factors significantly associated with rehospitalization were: EuroSCORE I [HR $=1.03,95 \%$ CI $(1.00-1.06), \mathrm{p}=0.008]$ and diabetes $[\mathrm{HR}=2.01,95 \% \mathrm{CI}(1.22-3.62), \mathrm{p}=0.007]$ (Table 1S in supplementary data).

In multivariable analysis, only diabetes was significantly associated with rehospitalization one year after the procedure by TAVR $[\mathrm{HR}=2.06,95 \%$ CI $(1.11-3.84)$, $\mathrm{p}=0.02]$ (Table 2).

\section{Secondary Outcome}

During 12-month follow-up, 10 patients died (5.1\%) of whom $60 \%$ were men, all of them had previously been hospitalized at least once. Only one of them had preoperative severe sarcopenia.

Univariable statistical analysis showed that neither severe sarcopenia, gait speed nor total SMI were associated with the occurrence of death $[\mathrm{HR}=2.04,95 \% \mathrm{CI}$ (0.25-16.39), $\mathrm{p}=0.49],[\mathrm{HR}=0.56,95 \%$ CI $(0.03-8.46)$,
$\mathrm{p}=0.67],[\mathrm{HR}=0.96,95 \%$ CI $(0.89-1.04), \mathrm{p}=0.37]$ (Table $\underline{2 \mathrm{~S}}$ in supplementary data). The pre-operative factors significantly associated with death in univariable analysis were EuroSCORE I [HR=1.05, 95\% CI (1.00-1.11), $\mathrm{p}=0.04]$, pulmonary hypertension $[\mathrm{HR}=4.96,95 \% \mathrm{CI}$ (1.39-17.58), $\mathrm{p}=0.01]$, and atrial fibrillation $[\mathrm{HR}=4.46$, 95\% CI (1.15-17.28), $\mathrm{p}=0.03$ ] (Table $2 \mathrm{~S}$ in supplementary data). No preprocedural factors were associated with mortality in multivariable Cox regression analysis (Table $3 \mathrm{~S}$ in supplementary data).

\section{Prevalence of Loss of Muscle Mass on CT- Scan and Prevalence of Severe Sarcopenia} Depending of the SMI threshold, prevalence of loss of muscle mass on CT-scan was heterogeneous and varied between $14.3 \%$ and $64.3 \%$ (Table 3 ).

\section{Discussion}

In this study, no association was found between severe sarcopenia (loss of muscle mass and altered gait speed) and rehospitalization one year after TAVR intervention. Altered physical performance defined by a gait speed $\leq 0.8 \mathrm{~m} / \mathrm{s}$ was associated 
Table I Baseline Characteristics of Patients $(\mathrm{N}=182)$ and With or Without Rehospitalization

\begin{tabular}{|c|c|c|c|c|}
\hline \multirow[t]{2}{*}{ Characteristics } & \multirow{2}{*}{$\begin{array}{c}\text { All Participants } \\
182\end{array}$} & \multicolumn{3}{|c|}{ Rehospitalization } \\
\hline & & Yes $=64$ & $\mathrm{No}=1 \mid \mathrm{8}$ & p-value \\
\hline $\mathrm{Age}^{\mathrm{a}}$ & $84(8 I-86)$ & $84(82-86)$ & $84(80-85)$ & 0.19 \\
\hline Male ${ }^{b}$ & $91(50)$ & $35(54.7)$ & $54(45.7)$ & 0.50 \\
\hline \multicolumn{5}{|l|}{ Baseline Characteristics } \\
\hline CIRS-G score ${ }^{a}$ & $9.0(7.0-11.0)$ & $9(8-11)$ & $9(7-11)$ & 0.16 \\
\hline Euroscore $\mathrm{I}^{\mathrm{a}}$ & $9.4(7.0-13.9)$ & $10.6(7.2-18.6)$ & $8.8(6.7-13)$ & 0.02 \\
\hline Euroscore II & $2.9(1.8-4.6)$ & $3.4(1.9-5.1)$ & $2.8(1.8-4.2)$ & 0.14 \\
\hline Cockcroft Renal clearance ${ }^{a}$ & $55.9(44.4-70.0)$ & $53(42-70)$ & $59(45-70)$ & 0.28 \\
\hline NYHA $\geq 3, n(\%)$ & $46(25.2)$ & $17(26.5)$ & $29(24.6)$ & 1 \\
\hline LVEF $^{a}$ & $60(54-65)$ & $60(55-65)$ & $61(55-65)$ & 0.20 \\
\hline Reduced LVEF ${ }^{b}$ & $24(13.2)$ & $10(15.6)$ & $13(11.0)$ & 0.59 \\
\hline Pulmonary hypertension ${ }^{\mathrm{b}}$ & $42(23.1)$ & $18(28.1)$ & $24(20.3)$ & 0.41 \\
\hline Atrial fibrillation ${ }^{b}$ & $63(34.6)$ & $24(37.5)$ & $36(30.5)$ & 0.58 \\
\hline Peripheral artery disease ${ }^{b}$ & $17(9.3)$ & $7(10.9)$ & $8(6.7)$ & 0.55 \\
\hline Diabetes $^{b}$ & $30(16.5)$ & $16(25.0)$ & $14(11.8)$ & 0.02 \\
\hline Coronary artery disease ${ }^{b}$ & $96(52.7)$ & $35(54.7)$ & $58(49.1)$ & 0.83 \\
\hline Body mass index ${ }^{a}$ & $26.4(23.8-29.6)$ & $26.6(24.1-29.9)$ & $26.3(24.1-30.3)$ & 0.56 \\
\hline Mini Nutritional Assessment ${ }^{a}$ & $25(24-26)$ & $25(24-26)$ & $25(24-26)$ & 0.38 \\
\hline Malnutrition* ${ }^{\mathrm{b}}$ & $9(4.9)$ & $2(3.1)$ & $6(5.1)$ & 0.71 \\
\hline Mini Mental Status score ${ }^{a}$ & $25(24-28)$ & $26(24-27)$ & $26(24-28)$ & 0.78 \\
\hline $\mathrm{ADL}^{\mathrm{a}}$ & $6(6-6)$ & $6(6-6)$ & $6(6-6)$ & 0.55 \\
\hline $\mathrm{IADL}^{\mathrm{a}}$ & $4(3-4)$ & $4(3-4)$ & $4(3-4)$ & 0.59 \\
\hline \multicolumn{5}{|l|}{ Sarcopenia data } \\
\hline Gait speed ${ }^{\text {a }}$ & $0.90 \pm 0.23$ & $0.85 \pm 0.25$ & $0.92 \pm 0.22$ & 0.10 \\
\hline Total SMI**, $\mathrm{cm}^{2} / \mathrm{m}^{2}$ a & $52.5 \pm 8.3$ & $53.1 \pm 8.1$ & $52.6 \pm 8.5$ & 0.64 \\
\hline Total SMRA**, UH ${ }^{\text {a }}$ & $25.1 \pm 14.5$ & $24.7 \pm 13.8$ & $25.3 \pm 12.1$ & 0.79 \\
\hline Severe Sarcopenia ${ }^{b}$ & $9(4.9)$ & $3(4.7)$ & $6(5.0)$ & 0.58 \\
\hline \multicolumn{5}{|l|}{ TAVR procedure } \\
\hline Femoral approach b & 167 (9I.7) & $58(90.6)$ & $104(88.1)$ & 0.81 \\
\hline Length of stay ${ }^{a}$ & $6(5-8)$ & $7(5-8)$ & $5(4-7)$ & 0.04 \\
\hline Rehabilitation & $37(20)$ & $15(23)$ & $22(18)$ & 0.56 \\
\hline
\end{tabular}

Notes: Significant $\mathrm{p}$-value (ie, $\mathrm{p}<0.05$ ) indicated in bold. *Malnutrition, BMI $\leq 21 \mathrm{~kg} / \mathrm{m}^{2}$ or MNA $<17$; **total: psoas, paraspinal and abdominal wall muscles; ${ }^{\mathrm{a}} \mathrm{median}$ (Interquartile Range), or mean \pm SD depending on normality; ${ }^{b}(\%)$.

Abbreviations: CIRS-G, Cumulative Illness Rating Scale-Geriatric (range 0 to 56); NYHA, New York Heart Association; LVEF, left ventricular ejection fraction; ADL, activity of daily living. IADL, instrumental activities of daily living; SMI, skeletal muscle index; SMRA, skeletal muscle mean attenuation.

with an increased risk of rehospitalization in univariable analysis. In multivariable analysis, only diabetes was significantly associated with rehospitalization.

Regarding rehospitalization, some studies reported that low muscle mass was a predictive factor of increased morbidity, early complications, and rehospitalization at 30 days in TAVR patients. $^{22,23}$ In the same way, Soud et al showed in a meta-analysis of 8 studies with 1881 patients, that a high muscle surface area was associated with lower long-term all-cause mortality after a TAVR. ${ }^{24}$ Several studies highlighted an association between low muscle surface area and the increased risk of mortality after a TAVR procedure, whether muscle surface area was total skeletal muscle surface area or psoas area. ${ }^{13-17}$ However, some studies did not find this association, probably due to confounding factors. ${ }^{18,25,26}$ Michel et al, for example, showed that patients with lower psoas area were older, had more comorbidities, and had higher surgical risk but without a significant association between psoas area and mortality. ${ }^{26}$ This variability in results could be explained by the lack of validated methodology for the CT-scan measurement of skeletal muscle surface area. The 
Table 2 Association of Preprocedural Factors with Rehospitalization One Year After Transcatheter Aortic Valve Implantation, in Multivariable Cox Regression

\begin{tabular}{|l|c|c|}
\hline \multirow{2}{*}{ Preprocedural Factors } & \multicolumn{2}{|c|}{ Rehospitalization } \\
\cline { 2 - 3 } & HR (95\% CI) & p-value \\
\hline Age & $1.04(0.96-I .12)$ & 0.29 \\
Male & $1.05(0.6 I-I .83)$ & 0.85 \\
EuroSCORE I & $1.03(0.99-1.06)$ & 0.06 \\
Left Ventricular Ejection Fraction & $0.99(0.96-1.02)$ & $0.4 I$ \\
Diabetes & $2.06(I . I I-3.84)$ & $\mathbf{0 . 0 2}$ \\
Severe Sarcopenia & $0.98(0.7 I-2.13)$ & 0.34 \\
\hline
\end{tabular}

Note: $\mathrm{p}$-value and hazard ratio $(\mathrm{HR})$ significant (ie, $\mathrm{p}<0.05$ ): indicated in bold.

vertebral level where muscle area measurements should be performed is not defined. Some authors used the level of the 3 rd or 4 th lumbar vertebra, sometimes the 12th thoracic vertebra. ${ }^{9,27}$ The muscle measurements were adjusted, or not, for height squared or body mass index. Moreover, the EWGSOP specifies that no value defining loss of muscle mass by CT-scan measurements has yet been validated even though the evaluation of muscle mass loss for sarcopenia by CT-scan can be considered as the gold standard. ${ }^{9}$ In our study, muscle measurements were performed at L3 level. The muscle surface area measured at this level is correlated to the whole body muscles and it is used in other medical specialties to evaluate prognostics and risk of mortality. ${ }^{9,28,29}$ The prevalence of sarcopenia in our population widely varied according to total SMI thresholds used, in the same way as in a recently published review. ${ }^{14}$

Physical performances assessed by gait speed are more often evaluated as prognostic factor. In our study, low gait speed was associated with an increased risk of rehospitalization. Our result is consistent with previous studies that showed an association between low gait speed and increased risk of mortality after a TAVR procedure. ${ }^{6,30}$ Alfredsson et al found that each decrease in gait speed of $0.2 \mathrm{~m} / \mathrm{s}$ corresponds to an $11 \%$ increase in mortality at 30 days. ${ }^{6}$ Gait speed was also associated with an increased risk of rehospitalization at 3 years. ${ }^{31}$ However, gait speed is a multidimensional concept that not only involves muscles but also central and peripheral nervous function. ${ }^{9}$ Therefore, it seemed interesting to add information on muscle quality to confirm sarcopenia diagnosis and to understand the underlying mechanism of this poor prognostic factor.

In this study, diabetes was a preprocedural factor associated with rehospitalization one year after TAVR procedure. Diabetes was already being identified as a marker of poor prognosis after cardiac surgery. ${ }^{32,33}$ However, studies showed that diabetes does not affect rates of complications following TAVR. ${ }^{32-34}$ In a meta-analysis including 28,440 patients, Ando et al showed that the risk of perioperative complications was similar between diabetic and non-diabetic cohorts. ${ }^{34}$ To explain this result, Conrotto et al

Table 3 Prevalence of Loss of Skeletal Muscle Mass on CT-Scan and Severe Sarcopenia According to Previously Published Threshold

\begin{tabular}{|c|c|c|c|}
\hline \multirow[t]{2}{*}{ Study (Year) } & \multirow{2}{*}{$\begin{array}{c}\text { CT-Scan Cut-Off for Loss of } \\
\text { Skeletal Muscle Mass for Men and } \\
\text { Women }\end{array}$} & \multicolumn{2}{|r|}{ Prevalence } \\
\hline & & $\begin{array}{l}\text { Loss of Skeletal } \\
\text { Muscle Mass on CT- } \\
\text { Scan }\end{array}$ & $\begin{array}{l}\text { Severe Sarcopenia (Loss of Skeletal Muscle } \\
\text { Mass on CT-Scan + Gait Speed }<0.8 \mathrm{~m} / \mathrm{sec} \text { ) }\end{array}$ \\
\hline $\begin{array}{l}\text { Dahya }(2016)^{15} \\
\text { Damluji }(2021)^{21}\end{array}$ & $\begin{array}{c}\text { Total SMI } \\
<55.0 \mathrm{~cm}^{2} / \mathrm{m}^{2} \text { in men } \\
<39.0 \mathrm{~cm}^{2} / \mathrm{m}^{2} \text { in women }\end{array}$ & $55(30.2 \%)$ & $9(4.9 \%)$ \\
\hline $\begin{array}{l}\text { Mok }(2016)^{19} \\
\text { Nemec }(2017)^{18} \\
\text { Heidari }(2019)^{16} \\
\text { Tokuda }(2020)^{20}\end{array}$ & $\begin{array}{c}\text { Total SMI } \\
<55.4 \mathrm{~cm}^{2} / \mathrm{m}^{2} \text { in men } \\
<38.9 \mathrm{~cm}^{2} / \mathrm{m}^{2} \text { in women }\end{array}$ & $56(30.7 \%)$ & $9(4.9 \%)$ \\
\hline Krishnan $(2019)^{17}$ & $\begin{array}{c}\text { Total SMI } \\
<50.0 \mathrm{~cm}^{2} / \mathrm{m}^{2} \text { in men } \\
<35.0 \mathrm{~cm}^{2} / \mathrm{m}^{2} \text { in women }\end{array}$ & $26(14.3 \%)$ & $4(2.2 \%)$ \\
\hline Mamane $(2019)^{13}$ & $\begin{array}{c}\text { Psoas SMA } \\
<20.3 \mathrm{~cm}^{2} \text { in men } \\
<11.8 \mathrm{~cm}^{2} \text { in women }\end{array}$ & II (64.3\%) & 36 (19.7\%) \\
\hline
\end{tabular}


explained that old patients had many comorbidities connected to each other, reducing the independent impact of diabetes on periprocedural complications. ${ }^{32}$

In our study, post-TAVR hospitalization was longer in patients who were readmitted in the following year. Length of hospital stay following TAVR was already known to be associated with 30-day rehospitalization. ${ }^{35,36}$ Its association with mid-term rehospitalization suggests that frailty, multiple comorbidities, and in-hospital complications may play an important role in increased rehospitalization rates in older patients rather than post-procedure complications.

This study has some important limitations. First, the mortality rate was low $(5.1 \%$ at 1 year $)$. In the Cardiology Department of the Nantes University Hospital, patients were selected after a strict pre-operative assessment including a preoperative geriatric assessment. As shown in Table 1, few patients had malnutrition $(<5 \%)$, mean gait speed was fairly high, and patients had few comorbidities. This careful patient selection may explain the low mortality rate. However, the primary purpose of our study was to examine the relationship between SMI and rehospitalization, which was still high (35\%). Second, the CT-scan measurements and the values defining loss of muscle on muscle surface area measurements were taken in studies but no cutoffs are widely recommended. Third, $20 \%$ of the population had geriatric personalized care plan with prehabilitation and/or rehabilitation after geriatric assessment. This care plan could include physical exercises which are recommended in case of low gait speed. Even though few patients had this individualized care plan, this might have participated in the absence of significant results.

In conclusion, even though our study failed to show association between severe sarcopenia and rehospitalization one year after TAVR, it has research implications. It highlights the need to define precisely the loss of muscle mass on CT-scan and to establish international threshold values for sarcopenia diagnosis by CT-scan measurements, in the general population and for patients with valvular heart disease.

\section{Funding}

There is no funding to report.

\section{Disclosure}

The authors reported no conflicts of interest for this work.

\section{References}

1. Nkomo VT, Gardin JM, Skelton TN, Gottdiener JS, Scott CG, Enriquez-Sarano M. Burden of valvular heart diseases: a population-based study. Lancet. 2006;368(9540):1005-1011. doi:10.1016/ S0140-6736(06)69208-8

2. Baumgartner H, Falk V, Bax JJ, et al. 2017 ESC/EACTS Guidelines for the management of valvular heart disease. Eur Heart J. 2017;38 (36):2739-2791. doi:10.1093/eurheartj/ehx391

3. Reardon MJ, Van Mieghem NM, Popma JJ, et al. Surgical or Transcatheter Aortic-Valve Replacement in Intermediate-Risk Patients. $N$ Engl J Med. 2017;376(14):1321-1331. doi:10.1056/ NEJMoa1700456

4. Zahn R, Werner N, Gerckens U, et al. Five-year follow-up after transcatheter aortic valve implantation for symptomatic aortic stenosis. Heart. 2017;103(24):1970-1976. doi:10.1136/heartjnl-2016-311004

5. Deeb GM, Reardon MJ, Chetcuti S, et al. 3-year outcomes in highrisk patients who underwent surgical or transcatheter aortic valve replacement. $J$ Am Coll Cardiol. 2016;67(22):2565-2574. doi:10.1016/j.jacc.2016.03.506

6. Alfredsson J, Stebbins A, Brennan JM, et al. Gait speed predicts 30day mortality following transcatheter aortic valve replacement: results from the society of thoracic surgeons/american college of cardiology transcatheter valve therapy registry ${ }^{\mathrm{tm}}$. Circulation. 2016;133 (14):1351-1359. doi:10.1161/CIRCULATIONAHA.115.020279

7. Afilalo J, Lauck S, Kim DH, et al. Frailty in older adults undergoing aortic valve replacement: the frailty-avr study. $\mathrm{J} \mathrm{Am} \mathrm{Coll} \mathrm{Cardiol.}$ 2017;70(6):689-700. doi:10.1016/j.jacc.2017.06.024

8. Rosenberg I. Epidemiologic and methodologic problems in determining nutritional status of older persons. (Summary comments). Am J Cli Nutr. 1989;50:1231-1233. doi:10.1093/ajen/50.5.1231

9. Cruz-Jentoft AJ, Bahat G, Bauer J, et al. Sarcopenia: revised European consensus on definition and diagnosis. Age Ageing. 2019;48(1):16-31. doi:10.1093/ageing/afy169

10. Cruz-Jentoft AJ, Landi F, Topinková E, Michel J-P. Understanding sarcopenia as a geriatric syndrome. Curr Opin Clin Nutr Metab Care. 2010;13(1):1-7. doi:10.1097/MCO.0b013e328333c1c1

11. Morley JE. Sarcopenia: diagnosis and treatment. J Nutr Health Aging. 2008;12(7):452-456. doi:10.1007/BF02982705

12. Goodpaster BH, Park SW, Harris TB, et al. The loss of skeletal muscle strength, mass, and quality in older adults: the health, aging and body composition study. J Gerontol a Biol Sci Med Sci. 2006;61 (10):1059-1064. doi:10.1093/gerona/61.10.1059

13. Mamane S, Mullie L, Lok Ok Choo W. Sarcopenia in Older Adults Undergoing Transcatheter Aortic Valve Replacement. J Am Coll Cardiol. 2019;74(25):3178-3180. doi:10.1016/j.jacc.2019.10.030

14. Bertschi D, Kiss CM, Schoenenberger AW, Stuck AE, Kressig RW. Sarcopenia in patients undergoing transcatheter aortic valve implantation (TAVI): a systematic review of the literature. $J$ Nutr Health Aging. 2021;25(1):64-70. doi:10.1007/s12603-020-1448-7

15. Dahya V, Xiao J, Prado CM, et al. Computed tomography-derived skeletal muscle index: a novel predictor of frailty and hospital length of stay after transcatheter aortic valve replacement. Am Heart J. 2016;182:21-27. doi:10.1016/j.ahj.2016.08.016

16. Heidari B, Al-Hijji MA, Moynagh MR, et al. Transcatheter aortic valve replacement outcomes in patients with sarcopenia. EuroIntervention. 2019;15(8):671-677. doi:10.4244/EIJ-D-19-00110

17. Krishnan A, Suarez-Pierre A, Zhou X, et al. Comparing frailty markers in predicting poor outcomes after transcatheter aortic valve replacement. Innovations. 2019;14(1):43-54. doi:10.1177/1556984519827698

18. Nemec U, Heidinger B, Sokas C, Chu L, Eisenberg RL. Diagnosing sarcopenia on thoracic computed tomography: quantitative assessment of skeletal muscle mass in patients undergoing transcatheter aortic valve replacement. Acad Radiol. 2017;24(9):1154-1161. doi:10.1016/j.acra.2017.02.008 
19. Mok M, Allende R, Leipsic J, et al. Prognostic value of fat mass and skeletal muscle mass determined by computed tomography in patients who underwent transcatheter aortic valve implantation. $\mathrm{Am}$ J Cardiol. 2016;117(5):828-833. doi:10.1016/j.amjcard.2015.12.015

20. Tokuda T, Yamamoto M, Kagase A, et al. Importance of combined assessment of skeletal muscle mass and density by computed tomography in predicting clinical outcomes after transcatheter aortic valve replacement. Int $J$ Cardiovasc Imaging. 2020;36(5):929-938. doi: 10.1007/s10554-020-01776-x

21. Damluji AA, Rodriguez G, Noel T, et al. Sarcopenia and healthrelated quality of life in older adults after transcatheter aortic valve replacement. Am Heart J. 2020;224:171-181. doi:10.1016/j. ahj.2020.03.021

22. Paknikar R, Friedman J, Cron D, et al. Psoas muscle size as a frailty measure for open and transcatheter aortic valve replacement. $J$ Thorac Cardiovasc Surg. 2016;151(3):745-751. doi:10.1016/j. jtcvs.2015.11.022

23. Garg L, Agrawal S, Pew T, et al. Psoas muscle area as a predictor of outcomes in transcatheter aortic valve implantation. Am J Cardiol. 2017;119(3):457-460. doi:10.1016/j.amjcard.2016.10.019

24. Soud M, Alahdab F, Ho G, et al. Usefulness of skeletal muscle area detected by computed tomography to predict mortality in patients undergoing transcatheter aortic valve replacement: a meta-analysis study. Int $J$ Cardiovasc Imaging. 2019;35(6):1141-1147. doi:10.1007/s 10554-019-01582-0

25. Hebeler KR, Baumgarten H, Squiers JJ, et al. Albumin is predictive of 1-year mortality after transcatheter aortic valve replacement. Ann Thorac Surg. 2018;106(5):1302-1307. doi:10.1016/j. athoracsur.2018.06.024

26. Michel J, Pellegrini C, Rheude T, et al. The clinical impact of psoas muscle cross-sectional area on medium-term mortality after transcatheter aortic valve implantation. Heart Lung Circ. 2020;29(6):904913. doi:10.1016/j.hlc.2019.05.095

27. Chen L-K, Woo J, Assantachai P, et al. Asian working group for sarcopenia: 2019 consensus update on sarcopenia diagnosis and treatment. J Am Med Dir Assoc. 2020;21(3):300-307.e2. doi:10.1016/j. jamda.2019.12.012
28. Carey EJ, Lai JC, Sonnenday C, et al. A North American Expert Opinion Statement on Sarcopenia in Liver Transplantation. Hepatology. 2019;70(5):1816-1829. doi:10.1002/hep.30828

29. Moisey LL, Mourtzakis M, Cotton BA, et al. Skeletal muscle predicts ventilator-free days, ICU-free days, and mortality in elderly ICU patients. Crit Care. 2013;17(5):R206. doi:10.1186/cc12901

30. Seiji K, Masanori Y, Tetsuro S, et al. Gait speed can predict advanced clinical outcomes in patients who undergo transcatheter aortic valve replacement. Circ Cardiovasc Interv. 2017;10(9):e005088. doi:10.1161/CIRCINTERVENTIONS.117.005088

31. Saji M, Higuchi R, Tobaru T, et al. Impact of frailty markers for unplanned hospital readmission following transcatheter aortic valve implantation. Circ J. 2017;82(8):2191-2198. doi:10.1253/circj.CJ17-0816

32. Conrotto F, D'Ascenzo F, Giordana F, et al. Impact of diabetes mellitus on early and midterm outcomes after transcatheter aortic valve implantation (from a multicenter registry). Am J Cardiol. 2014;113(3):529-534. doi:10.1016/j.amjcard.2013.10.025

33. Abramowitz Y, Jilaihawi H, Chakravarty T, et al. Impact of diabetes mellitus on outcomes after transcatheter aortic valve implantation. Am J Cardiol. 2016;117(10):1636-1642. doi:10.1016/j. amjcard.2016.02.040

34. Ando T, Takagi H, Briasoulis A, Umemoto T. Does diabetes mellitus impact prognosis after transcatheter aortic valve implantation? Insights from a meta-analysis. $J$ Cardiol. 2017;70(5):484-490. doi:10.1016/j.jjcc.2017.01.005

35. Arora S, Hendrickson MJ, Strassle PD, et al. Trends in costs and risk factors of 30-day readmissions for transcatheter aortic valve implantation. Am J Cardiol. 2020;137:89-96. doi:10.1016/j. amjcard.2020.09.041

36. Sanchez CE, Hermiller JB, Pinto DS, et al. Predictors and risk calculator of early unplanned hospital readmission following contemporary self-expanding transcatheter aortic valve replacement from the STS/ACC TVT Registry. Cardiovasc Revascularization Med. 2020;21(3):263-270. doi:10.1016/j.carrev.2019.05.032
Clinical Interventions in Aging

\section{Publish your work in this journal}

Clinical Interventions in Aging is an international, peer-reviewed journal focusing on evidence-based reports on the value or lack thereof of treatments intended to prevent or delay the onset of maladaptive correlates of aging in human beings. This journal is indexed on PubMed Central, MedLine, CAS, Scopus and the Elsevier

\section{Dovepress}

Bibliographic databases. The manuscript management system is completely online and includes a very quick and fair peer-review system, which is all easy to use. Visit http://www.dovepress.com/ testimonials.php to read real quotes from published authors. 